DOI: $10.37190 /$ epe 170204

\title{
THE EFFECT OF IONIC LIQUIDS WITH THE TETRAFLUOROBORATE ANION ON TERRESTRIAL PLANTS
}

\begin{abstract}
Ionic liquids have attracted considerable interest as excellent alternatives to organic solvents to be used in homogeneous and biphasic processes. Ionic liquids are non-volatile, non-flammable and their "green" character has usually been justified with their negligible vapour pressure. However, the marketing of any chemical substance requires the determination of their impact on all elements of nature. Determination of the potential ecotoxicity of new chemical compounds is associated with conducting research on the effects of those compounds on the growth and development of selected organism. The phytotoxic properties of chiral ionic salts with the alkylimidazolium cation and the tetrafluoroborate anion were assessed for selected weeds popular in Poland: gallant soldier (Galinsoga parviflora Cav.), white goosefoot (Chenopodium album L.) and common sorrel (Rumex acetosa L.). It was found that 3alkyl-1-[(1R,2S,5R)-(-)-menthoxymethyl]imidazolium tetrafluoroborates - ([C 8 -Im-Men][BF 4$)$ and $\left(\left[\mathrm{C}_{9}-\mathrm{Im}-\mathrm{Men}\right]\left[\mathrm{BF}_{4}\right]\right)$ were low toxic to plants. A higher toxicity to terrestrial plants was characterized by $\left(\left[\mathrm{C}_{11}-\mathrm{Im}-\mathrm{Men}\right]\left[\mathrm{BF}_{4}\right]\right)$. The toxicity effect of compounds depended non only on the length of the alkyl chain in the function group but also on the concentration of the used compound and the type of plant which was sprayed with the tested compound.
\end{abstract}

\section{INTRODUCTION}

Green chemistry can be a base for designing chemical substances, including recreation media, which are safe for the environment and man. A trend exists to eliminate,

${ }^{1}$ Institute of Chemistry, Environmental Protection and Biotechnology, Jan Długosz University in Częstochowa, al. Armii Krajowej 13/15, 42-200 Częstochowa, Poland, corresponding author R. Biczak, e-mail address: r.biczak@ajd.czest.pl

${ }^{2}$ Faculty of Mechanical and Power Engineering, Wrocław University of Science and Technology, Wybrzeże Wyspiańskiego 27, 50-370 Wrocław, Poland.

${ }^{3}$ Faculty of Chemistry, Wrocław University of Science and Technology, Wybrzeże Wyspiańskiego 27, 50-370 Wrocław, Poland. 
and where possible, to minimise the use of harmful substances, mainly classical solvents emitting toxic vapours in all industry branches including organic synthesis. Ionic liquids (ILs) are considered a perfect alternative for highly volatile and toxic organic solvents. In recent years, thanks to their physicochemical properties, such as low vapour pressure, incombustibility, high thermal stability, high ionic conductivity and good catalytic properties and practically perfect dissolving power for organic and inorganic materials, ionic liquids are applied on a large scale [1-3].

Initially ionic liquids were considered to be completely safe for the environment. However, extensive research has shown that this preliminary thesis was not true and that these compounds are toxic to both the natural environment in its broadest sense and to human health. The commercial use of ionic liquids, regardless of their composition and properties, results in the need to test ILs influence on the environment. It should be conducted simultaneously with the research on possible applications of these compounds as complete elimination of the natural environment pollution seems impossible. Ionic liquids pose a serious threat to the soil environment which they can reach as postproduction wastes, wastewater discharge, dump effluents, etc. After reaching the soil, the compounds can substantially influence the development of soil organisms and the growth and quality of terrestrial plants, hence there is some literature on the subject of phytotoxicity of ionic liquids [4-6].

Simultaneously, the toxic influence of ionic liquids on selected plant species is used, e.g., in herbicide preparations. The basic problem related to the use of traditional MCPA or 2,4-D type herbicide formulations is their toxicity to animals and people which was confirmed in scientific research [7] . Due to the above there is a need for constant searching for chemical compounds exhibiting selective herbicide properties accompanied by a lack of toxicity to people and all elements of the natural environment. An alternative for traditionally used plant protection products can be herbicidal ionic liquids (HILs) [8], defined also as phytopharmaceuticals. They are third-generation ionic liquids. These compounds show better biological properties than classical herbicides used so far. HILs have very good thermal and chemical stability, they are less soluble in water which decreases the possibility of contaminating surface and ground waters. Another benefit resulting from using HILs, in comparison with traditional herbicides is the possibility to decrease the active substance dosage. It significantly increases the safety of the used compounds, and economically justifies the use of herbicides in agricultural practice [9, 10].

In the presented work, the influence of ILs containing in their structure a component naturally occurring in the environment, namely $(1 R, 2 S, 5 R)-(-)$-menthol, on the growth and development of three commonly occurring weed species: G. parviflora, $C$. album and $R$. acetosa was determined. The compounds selected for the research were tetrafluoroborate salts with a longer alkyl function groups (from $\mathrm{C}_{8} \mathrm{H}_{17}$ to $\mathrm{C}_{11} \mathrm{H}_{23}$ ) at the pyrrole-type nitrogen atom in the imidazolium ring (Fig. 1). 


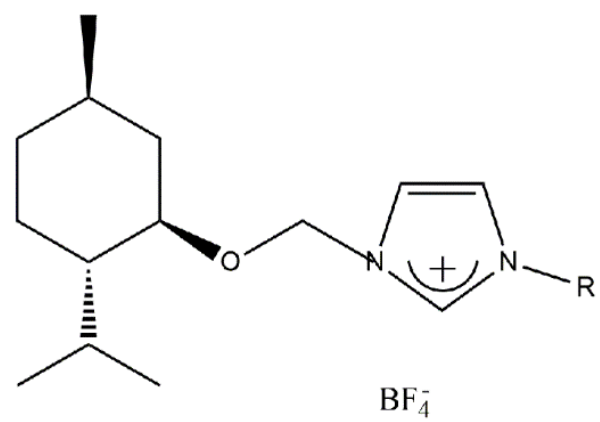

Fig. 1. The general formula of the tested chiral salts

The synthesis and physicochemical properties of 3-alkyl-1-[(1R,2S,5R)-(-)-menthoxymethyl]imidazolium tetrafluoroborates have been presented elsewhere [11]. The basic structural element of surface active compounds selected for the research on herbicidal properties is $(1 R, 2 S, 5 R)-(-)$-menthol, a saturated alcohol which is widely used in food, pharmaceutical, cosmetic and chemical industries [12]. This cyclic terpene compound is an invaluable component of numerous consumer products, such as toothpaste, cooling ointments, creams, deodorants, chewing gum, cigarettes, etc. In contact with skin or mucosa, it shows a strong cooling effect giving a soothing fresh feeling. The described monoalcohol with a strong odour occurs at high concentration (about $50 \%$ of oil) in Lamiaceae species, e.g. in Mentha piperita or its varieties. Undoubtedly (-)-menthol is the bestselling aromatic substance in the world. Over the years, one can observe an increase in the demand for this terpene alcohol; currently the demand is estimated at the level of 30000 tonnes a year. It is related to the unique properties of menthol. It should be emphasised here that the price of this aromatic compound is very reasonable. Hence the synthesis of products which can have an industrial application in the future and contain this component are economically justified.

Previously we have described the properties of quaternary ammonium salts with $(1 R, 2 S, 5 R)-(-)-m e n t h o l$ functional group: biocidal [13], antielectrostatic properties [11], stabilising and activating effect of enzymes [14] and catalytic chemical processes [15]. The listed compounds belongs to the ILs.

Imidazole salts with $(1 R, 2 S, 5 R)-(-)$-menthol functional group and the tetrafluoroborate group in the anion which are the subject of this work, were tested for phytotoxicity using terrestrial plants: spring barley (Hordeum vulgare) - a monocotyledon plant and common radish (Raphanus sativus L. subvar. radicula Pers.) - a dicotyledon plant [16]. Based on the reported research [16], it was found out that the toxicity of tetrafluoroborates to plants and the magnitude of the toxic effect depended, among others, on the functional group length and the used concentration. However, currently there are 
no scientific reports describing the reaction of terrestrial plants to the use of tetrafluoroborate salts with functional groups (from $\mathrm{C}_{8} \mathrm{H}_{17}$ to $\mathrm{C}_{11} \mathrm{H}_{23}$ ) being sprayed on leaves, hence the decision to start the research.

Moreover the choice of ILs with the tetrafluoroborate group in the anion part seems to be fully justified as, according to Barrado et al. [17] and Zhang et al. [18], IL tetrafluoroborate salts are often used in chemical synthesis, catalysis and electrochemistry. When they are used as solvents, they perfectly stabilise the environment, thus they are commonly used in tests and enzymatic processes [19,20]. The selection of ionic salts with the tetrafluoroborate anion was based also on the literature information on high toxicity of these anions which is a consequence of the introduction of hydrogen fluoride, a compound very toxic to organisms, to the environment as a result of hydrolysis [6, 21].

For that reason, it seems extremely interesting to test and determine the influence of 3-alkyl-1-[(1R,2S,5R)-(-)-menthoxymethyl]imidazolium tetrafluoroborates on selected types of weeds. The experimental results will allow us to assess the risk of the natural environment pollution after the possible use of these substances, especially that not many papers are available which would fall into this scope of research. The results of the research will also allow us to indicate substances which can become an alternative for classical plant protection products.

\section{EXPERIMENTAL}

Characterization and analysis of compounds. For all measurements chiral ILs with the alkylimidazolium cation with $(1 R, 2 S, 5 R)-(-)$-menthol component and the tetrafluoroborate anion were used, and their chemical formulae are presented in Fig. 2.

All reagents and solvents were obtained from the commercial suppliers and were dried using standard techniques. Imidazole was freshly recrystallized from benzene (with the melting temperature $90-91^{\circ} \mathrm{C}$ ). The alkylimidazoles were prepared according to the published method [11] and purified by vacuum distillation. The preparation of 3-alkyl-1-[(1R,2S,5R)-(-)-menthoxymethyl]imidazolium tetrafluoroborates ([Cn-Im-Men] $\left.\left[\mathrm{BF}_{4}\right]\right)\left(\mathrm{Cn}\right.$ being $\left.\mathrm{C}_{8} \mathrm{H}_{17}, \mathrm{C}_{9} \mathrm{H}_{19}, \mathrm{C}_{11} \mathrm{H}_{23}\right)$ followed the published method [11]. The salts were crystallized in water/ethanol and dried at $40{ }^{\circ} \mathrm{C}$ for $48 \mathrm{~h}$ under vacuum. ${ }^{1} \mathrm{H}$ and

${ }^{13} \mathrm{C}$ NMR spectra were recorded on a Bruker DRX with tetramethylsilane as the standard (at 300 and $75 \mathrm{MHz}$, respectively).

For the purpose of confirming the purity of the obtained chiral tetrafluoroborates, the content of the surface active compound was determined using the two phase titration (EN ISO 2871-2:2010) [22]. The elementary analysis was conducted for all compounds. The melting temperature of the discussed salts was determined using Digi-Melt MPA 161 melting point apparatus. 


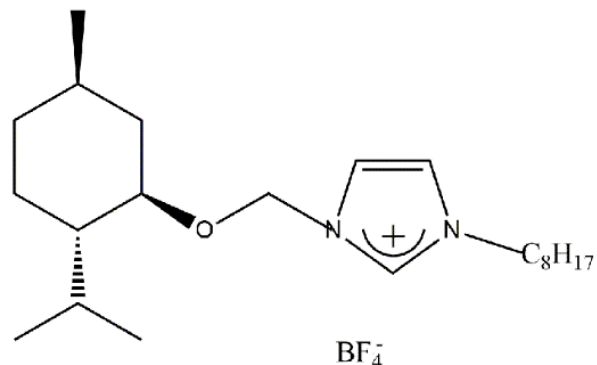

$1-[(1 R, 2 S, 5 R)-(-)$-menthoxymethyl $]$ -3-octylimidazolium tetrafluoroborate

Fig. 2. Structures of 3-alkyl-1-[(1R,2S,5R)-(-)-menthoxymethyl]imidazolium tetrafluoroborates

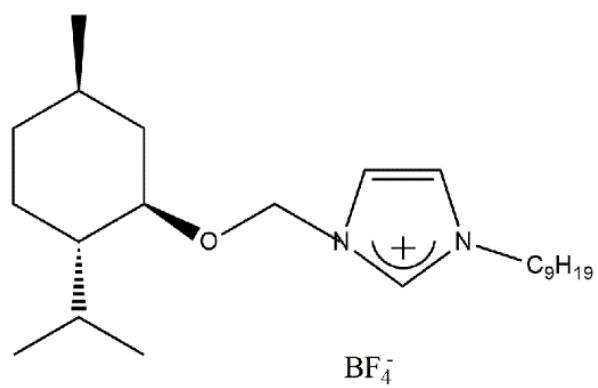

$1-[(1 R, 2 S, 5 R)-(-)$-menthoxymethyl $]$ -3-nonylimidazolium tetrafluoroborate

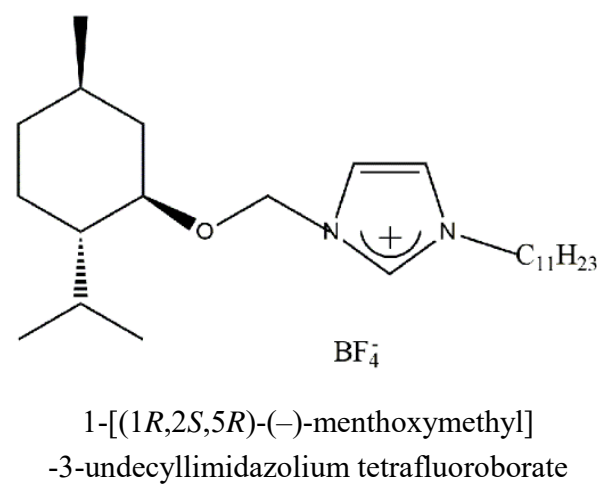

Toxicity tests of alkylimidazolium tetrafluoroborates. The research related to the determination of the influence of chiral 1-alkylmidazolium liquids sprayed on the leaves of selected weeds was conducted in a vegetation hall at the Department of Biochemistry and Ecotoxicology, Jan Długosz University in Częstochowa. The soil used in the experiment was light loam with a dissolved matter contain of approx. $10 \mathrm{wt} . \%$, an organic carbon of $9.0 \mathrm{~g} \mathrm{~kg}^{-1}$ and $\mathrm{pH}$ equal to 6.0. Over the whole period of research the substrate humidity was maintained at the level required by the plants ( $70 \%$ of field capacity), constant temperature $20 \pm 2{ }^{\circ} \mathrm{C}$ and illumination level of 7000 lux in the 16 hours/day and 8 hours/night.

The same amount (determined gravimetrically) of gallant soldier (Galinsoga parviflora Cav.), white goosefoot (Chenopodium album L.) and common sorrel (Rumex acetosa L.) seeds were sown in flower pots, $90 \mathrm{~mm}$ diameter, with soil. After 3 weeks from sprouting, the plants were sprayed with the solutions of appropriate ionic salts. Sprayed compounds were in the form of water-methanol solutions $(0.5,1.0$, and $2.0 \mathrm{wt}$. \%). Controls were prepared in same way: the leaves were sprayed with water-methanol solutions without adding the compound. The research was conducted for 14 days after spraying. 
The indicator of potential phytotoxic properties of tetrafluoroborates was visual assessment of growth inhibition, weed damage or drying.

\section{RESULTS AND DISCUSSION}

As a result of the conducted syntheses, three ionic liquids with natural component were obtained. The conducted NMR spectroscopy confirmed the structures of the obtained salts which were comparable with the ones presented earlier [11]. The synthesised optically active tetrafluoroborates were non-hygroscopic solids of clearly hydrophobic nature. Another characteristic feature of these substances was menthol-imidazolium odour. The reactions of obtaining the discussed salts were technologically acceptable and were in the range of $98.5-99 \%$. The melting temperatures of the tested salts were low and did not exceed $80{ }^{\circ} \mathrm{C}$ (Table 1). The contents of cation-active substance in the synthesised tetrafluoroborates was in the range of 98.9-99.8\%. Table 1 shows the reaction yields, melting temperatures of the obtained salts as well as the results of two phase titration and elementary analyses.

Table 1

The yield, surfactant content, empirical formula, elementary analysis for tested ionic liquids

\begin{tabular}{|c|c|c|c|c|c|c|}
\hline \multirow{2}{*}{ Ionic liquid } & \multirow{2}{*}{$\begin{array}{l}\text { Yield } \\
{[\%]}\end{array}$} & \multirow{2}{*}{$\begin{array}{l}\text { Melting point } \\
\qquad\left[{ }^{\circ} \mathrm{C}\right]\end{array}$} & \multirow{2}{*}{$\begin{array}{c}\text { Surfactant } \\
\text { content } \\
{[\%]}\end{array}$} & \multirow{2}{*}{$\begin{array}{l}\text { Empirical } \\
\text { formula }\end{array}$} & \multicolumn{2}{|c|}{$\begin{array}{c}\text { Elemental composition } \\
{[\%]}\end{array}$} \\
\hline & & & & & Calculated & Found \\
\hline$\left[\mathrm{C}_{8}-\mathrm{Im}-\mathrm{Men}\right]\left[\mathrm{BF}_{4}\right]$ & 99.0 & $77-79$ & 99.8 & $\mathrm{C}_{22} \mathrm{H}_{41} \mathrm{BF}_{4} \mathrm{~N}_{2} \mathrm{O}$ & $\begin{array}{l}\text { C } 60.54 \\
\text { H } 9.49 \\
\text { N } 6.42 \\
\end{array}$ & $\begin{array}{l}\text { C } 60.42 \\
\text { H } 9.53 \\
\text { N } 6.47 \\
\end{array}$ \\
\hline$\left[\mathrm{C}_{9}-\mathrm{Im}-\mathrm{Men}\right]\left[\mathrm{BF}_{4}\right]$ & 98.5 & $70-71$ & 98.9 & $\mathrm{C}_{23} \mathrm{H}_{43} \mathrm{BF}_{4} \mathrm{~N}_{2} \mathrm{O}$ & $\begin{array}{l}\text { C } 61.32 \\
\text { H } 9.64 \\
\text { N } 6.22 \\
\end{array}$ & $\begin{array}{l}\text { C } 61.49 \\
\text { H } 9.51 \\
\text { N } 6.15\end{array}$ \\
\hline$\left[\mathrm{C}_{11}-\mathrm{Im}-\mathrm{Men}\right]\left[\mathrm{BF}_{4}\right]$ & 99.0 & $28-30$ & 99.3 & $\mathrm{C}_{25} \mathrm{H}_{47} \mathrm{BF}_{4} \mathrm{~N}_{2} \mathrm{O}$ & $\begin{array}{l}\text { C 62.74 } \\
\text { H } 9.92 \\
\text { N } 5.58\end{array}$ & $\begin{array}{l}\text { C } 62.59 \\
\text { H } 10.05 \\
\text { N } 5.47\end{array}$ \\
\hline
\end{tabular}

The purity of the salts was confirmed by the elementary analyses. The agreement between the experimental data and results of calculation was satisfactory; the differences did not exceed $\pm 0.17 \%$ for $\mathrm{C}, \pm 0.13 \%$ for $\mathrm{H}$ and $\pm 0.11 \%$ for $\mathrm{N}$.

The results obtained from the performed experiments, spraying of the solutions of ionic salts on gallant soldier (Galinsoga parviflora Cav.), white goosefoot (Chenopodium album $\mathrm{L}$.) and common sorrel (Rumex acetosa $\mathrm{L}$.) proved that the tested substances can be considered compounds with low toxicity effect toward these weeds. The degree 
of such effect depended on the used compound concentration, functional group length and plant type.

$1-\left[(1 R, 2 S, 5 R)-(-)\right.$-menthoxymethyl]-3-octylimidazolium tetrafluoroborate, $\left[\mathrm{C}_{8}-\mathrm{Im}\right.$ $-\mathrm{Men}]\left[\mathrm{BF}_{4}\right]$ used at the concentration of 0.5 and $1.0 \mathrm{wt}$. \% practically does not have a phytotoxic effect on the tested weeds. Only the $2.0 \%$ solution of the salt with the octyl functional group led to chlorotic and necrotic changes on weed leaves (Fig. 3). Apart from a small influence on white goosefoot (Chenopodium album L.), 1-[(1R,2S,5R) -(-)-menthoxymethyl]-3-nonylimidazolium tetrafluoroborate did not show any harmful effect on the tested weeds (Fig. 4).

White goosefoot

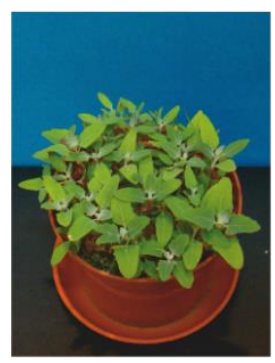

Control

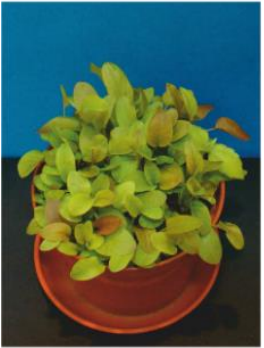

Control

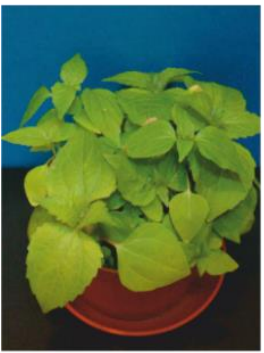

Control

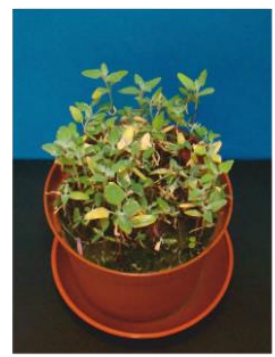

$0.5 \%$

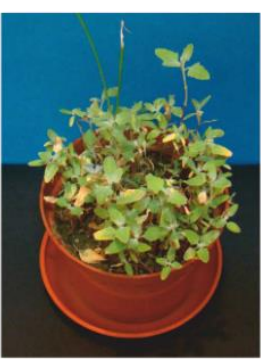

$1.0 \%$

Common sorrel

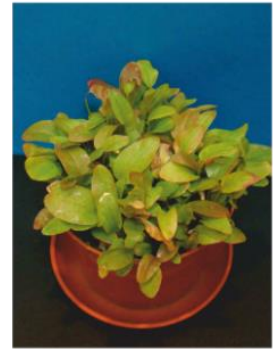

$0.5 \%$

Gallant soldier

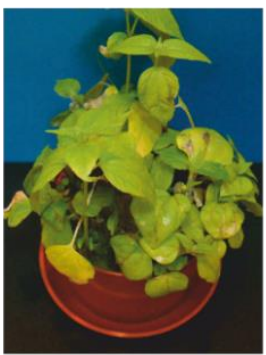

$0.5 \%$

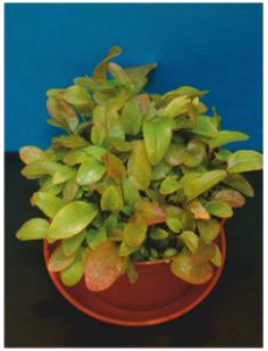

$1.0 \%$

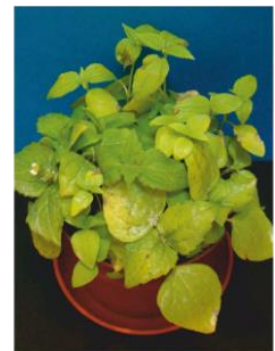

$1.0 \%$

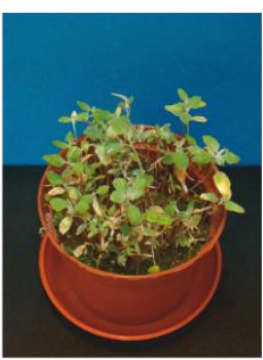

$2.0 \%$

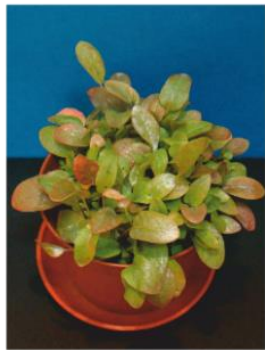

$2.0 \%$

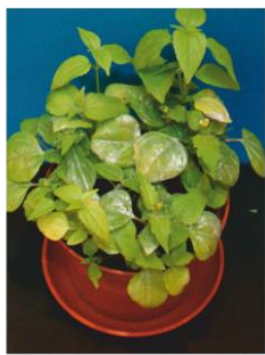

$2.0 \%$

Fig. 3. Reaction of plants 14 days after spraying $0.5,1.0$ and $2.0 \%$ solutions of 1-[(1R,2S,5R)-(-)-menthoxymethyl]-3-octylimidazolium tetrafluoroborate [C8-Im-Men][BF4] 
White goosefoot

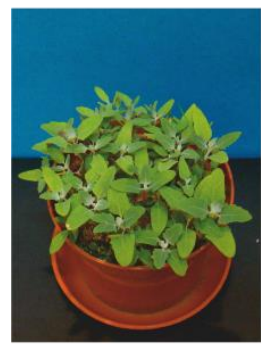

Control

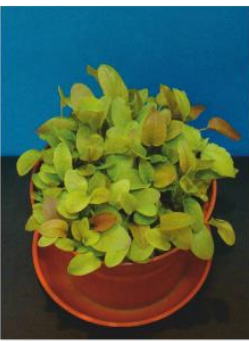

Control

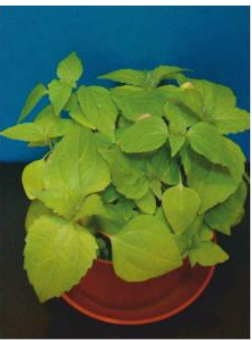

Control

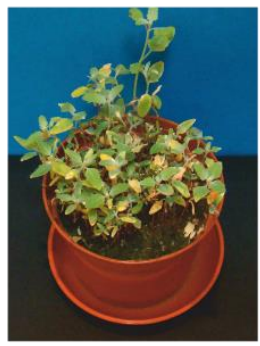

$0.5 \%$

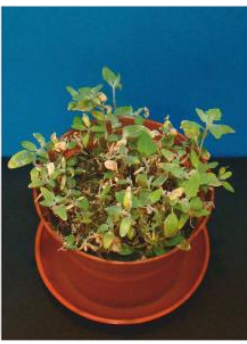

$1.0 \%$

Common sorrel

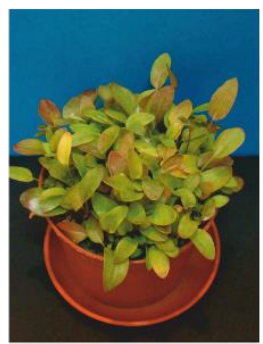

$0.5 \%$

Gallant soldier

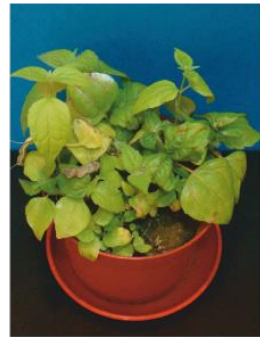

$0.5 \%$

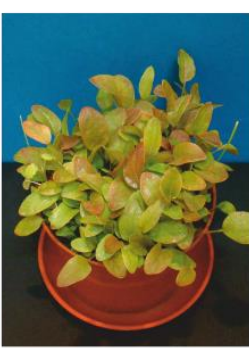

$1.0 \%$

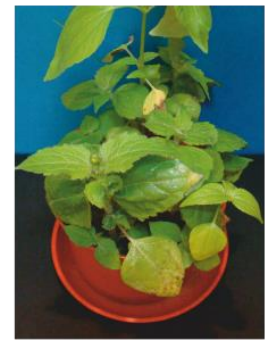

$1.0 \%$

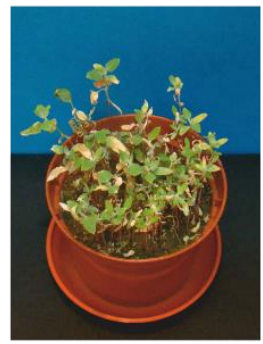

$2.0 \%$

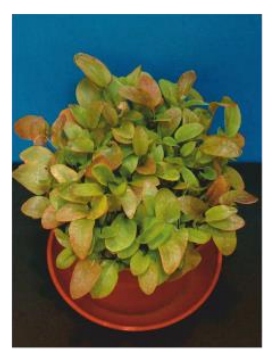

$2.0 \%$

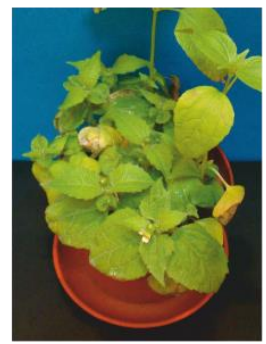

$2.0 \%$

Fig. 4. Reaction of plants 14 days after spraying $0.5,1.0$ and $2.0 \%$ solutions of 1-[(1R,2S,5R)-(-)-menthoxymethyl]-3-nonylimidazolium tetrafluoroborate [C9-Im-Men] $\left[\mathrm{BF}_{4}\right]$

As opposed to the previous compound, 1-[(1R,2S,5R)-(-)-menthoxymethyl]-3-undecyllimidazolium tetrafluoroborate exhibited a relatively strong toxic effect on white goosefoot (Chenopodium album L.). At the lowest concentration of $0.5 \mathrm{wt}$. $\%$, the plants dried after 4 days, whereas when $1.0 \mathrm{wt} . \%$ and $2.0 \mathrm{wt} . \%$ solutions were used, goosefoot plants withered only 2 days after spraying. A weaker effect of $\left[\mathrm{C}_{11}-\mathrm{Im}-\mathrm{Men}\right]\left[\mathrm{BF}_{4}\right]$ was shown in the case of common sorrel (Rumex acetosa L.), however, the higher the concentration of the substance in the ionic liquid, the stronger the salt effect and the greater changes can be observed in plants. Nevertheless, even when the solutions of the highest 


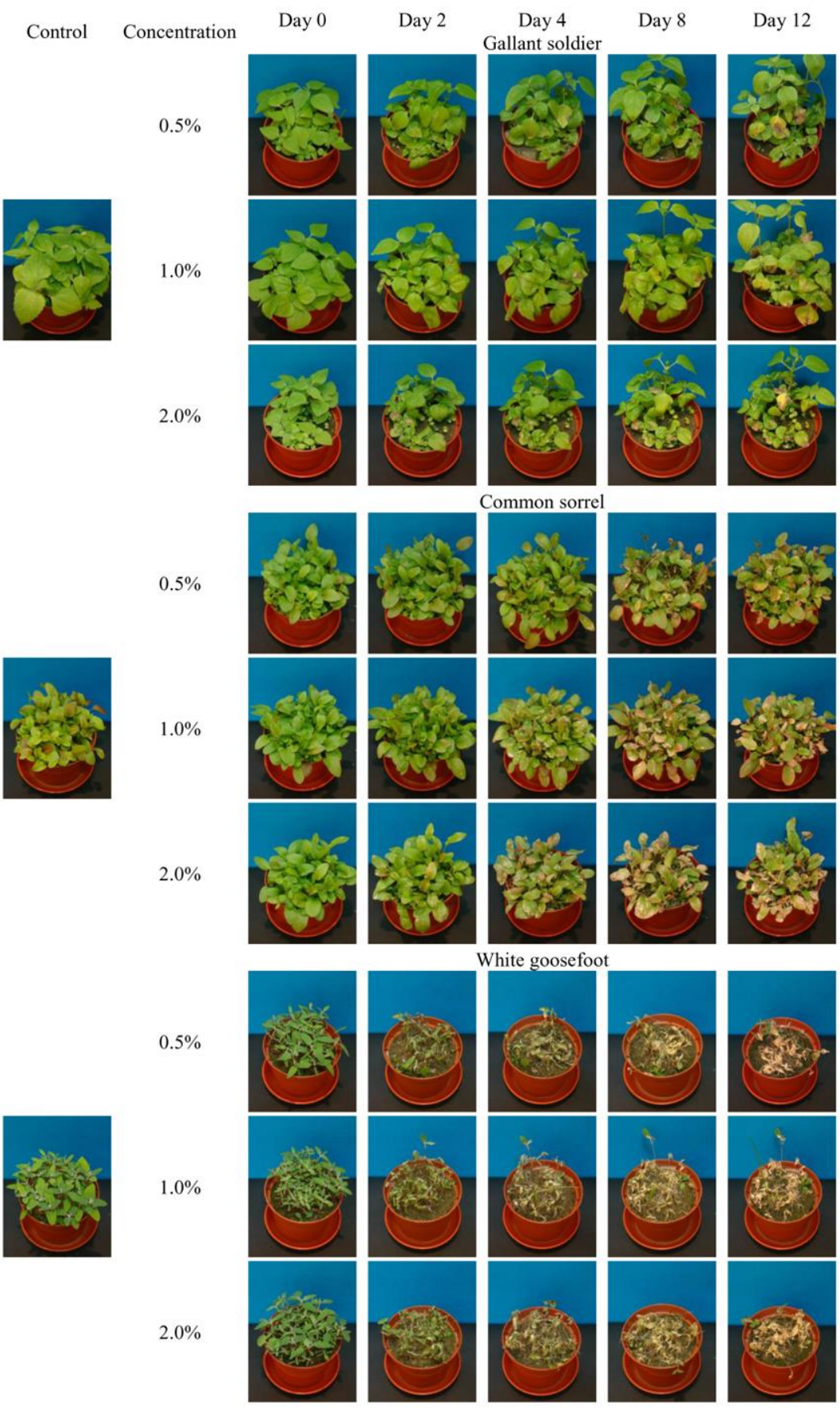

Fig. 5. Reaction of plants on spraying with $0.5 \mathrm{wt} . \%, 1.0 \mathrm{wt}$ \% and $2.0 \mathrm{wt}$ \% solutions of 1-[(1R,2S,5R)-(-)-menthoxymethyl]-3-undecyllimidazolium tetrafluoroborate [C11-Im-Men][BF4] 
concentration were used, only half of the plants withered. The compound had the smallest effect on gallant-soldier, even at the highest concentration (2.0 wt. \%), only small changes appeared on the leaves and only some plants withered (Fig. 5).

The results of the research have shown that the toxic effect of chemical substances on terrestrial plants depends on their concentration. Similar opinion has been presented in the literature for different group of the ionic liquids [23]. Another factor conditioning the toxicity of chemical substances are of plant species and varieties [4, 24, 25], which was also confirmed in this work.

\section{CONCLUSION}

Selected optically active ionic liquids sprayed on the leaves of gallant-soldier, white-goosefoot and sorrel show low phytotoxic properties with reference to the early development stages of these plants. The compounds with octyl and nonyl functional groups are practically non-toxic for the tested plant species, while the influence of 1 -[(1R,2S,5R)-(-)-menthoxymethyl]-3-undecylimidazolium tetrafluoroborate on weeds largely depends on the plant species. The toxic influence of the used ionic liquids depended also on the used substance concentration in suspension with which the leaves of terrestrial plants were sprayed. This effect of the use of $\left[\mathrm{C}_{11}-\mathrm{Im}-\mathrm{Men}\right]\left[\mathrm{BF}_{4}\right]$ is very promising in the aspect of the potential use of this ionic salt as a biologically active substance, e.g.in agriculture forestry. Salts with such biological activity can decrease the amount of chemical agents in the environment and limit the eco-toxic effect which always accompanies the use of conventional plant protection agents.

1-[(1R,2S,5R)-(-)-menthoxymethyl]-3-octylimidazolium and 1-[(1R,2S,5R)-(-)-1-menthoxymethyl]-3-nonylimidazolium tetrafluoroborates thanks to their small influence on terrestrial plants can be used in industry as compounds which are relatively safe for the natural environment.

The results of the presented research can be also useful in the assessment of the potential risk to other elements of the natural environment, not only plants. They can also be used to design low toxicity substances which are extremely useful in industry and agriculture.

\section{ACKNOWLEDGEMENTS}

The work was financed by a statutory activity subsidy from the Polish Ministry of Science and Higher Education for the Faculty of Chemistry and the Faculty of Mechanical and Power Engineering of Wrocław University of Science and Technology and the Faculty of Mathematics and Natural Sciences of Jan Dhugosz University in Częstochowa. 


\section{REFERENCES}

[1] Plechkova V., Seddon K.R., Applications of ionic liquids in the chemical industry, Chem. Soc. Rev., 2008, 37 (1), 123.

[2] Beste Y., Eggersmann M., Schoenmakers H., Extractive distillation $C$ with ionic liquids, Chem. Ing. Tech., 2005, 77, 1800.

[3] Zhang S., Dokko K., Watanabe M., Porous ionic liquids. Synthesis and application, Chem. Sci., 2015, 6, 3684.

[4] Biczak R., PawŁowska B., BaŁCZewski P., Rychter P., The role of the anion in the toxicity of imidazolium ionic liquids, J. Hazard. Mater., 2014, 274, 181.

[5] Biczak R., BaŁczewski P., Bachowska B., PawŁowska B., Kazmierczak-Baranska J., Cieslak M., NAwrot B., Phytotoxicity and cytotoxicity of imidazolium ionic liquids containing sulfur atoms, Phosph. Sulfur Silicon Relat. Elem., 2013, 188, 459.

[6] Cvjetko Bubalo M., Radošević K., Redovniković I.R., Halambek J., SrČek V.G., A briefoverview of the potential environmental hazards of ionic liquids, Ecotoxicol. Environ. Saf., 2014, 99, 1.

[7] Kimura O., Tsukagoshi K., Endo T., Uptake of phenoxyacetic acid derivatives into Caco-2 cells by the monocarboxylic acid transporters, Toxicol. Lett., 2009, 189, 102.

[8] Praczyk T., Pernak J., Herbicidal ionic liquids, Przem. Chem., 2013, 92, 1660 (in Polish).

[9] Polit J.T., Praczyk T., Pernak J., Sobiech Ł., Jakubiak E., Skrzypczak G., Inhibition of germination and early growth of rape seed (Brassica napus L.) by MCPA in anionic and ester form, Acta Physiol. Plant., 2014, 36, 699.

[10] Kordala-Markiewicz R., Rodak H., Markiewicz B., Walkiewicz F., Sznajdrowska A., Materna K., Marcinkowska K., Praczyk T., Pernak J., Phenoxy herbicidal ammonium ionic liquids, Tetrahedron, 2014, 70 (32), 4784.

[11] Pernak J., Feder-Kubis J., Cieniecka-RosŁonkiewicz A., Fischmeister C., Grifin S.T., Rogers R.D., Synthesis and properties of chiral imidazolium ionic liquids with a $(1 R, 2 S, 5 R)-(-)$-menthoxymethyl substituent, New J. Chem., 2007, 31, 879.

[12] ECCLES R., Role of cold receptors and menthol in thirst, the drive to breathe and arousal, Appetite, 2000, 34 (1), 29.

[13] Feder-Kubis J., TOMCZUK K., The effect of the cationic structures of chiral ionic liquids on their antimicrobial activities, Tetrahedron, 2013, 69 (3-4), 4190.

[14] FEDER-KUBIS J., BRYJAK J., Laccase activity and stability in the presence of menthol-based ionic liquids, Acta Biochim. Pol., 2013, 60 (4), 741.

[15] Miao X., Feder-Kubis J., Fischmeister C., Pernak J., Dixneuf P., Catalytic cycloisomerisation of 1,6-dienes in ionic liquids, Tetrahedron, 2008, 64, 3687.

[16] Biczak R., PawŁowska B., Feder-KuBIS J., The phytotoxicity of ionic liquids from natural pool of (-)-menthol with tetrafluoroborate anion, Environ. Sci. Pollut. Res., 2015, 22 (15), 11740.

[17] Barrado E., Couto R.A.S., Quinaz M.B., Lima J.L.F.C., CASTRILlejo Y., Electrochemical behaviour of ferrocene in the ionic liquid 1-ethyl-3-methylimidazolium tetrafluoroborate, EMIMBF 4 , at 298 K, J. Electroanal. Chem., 2014, 720-721, 136.

[18] Zhang C., Malhorta S.V., Francis A.J., Toxicity of ionic liquids to Clostridium sp. and effects on uraniumbiosorption, J. Hazard. Mater., 2014, 264, 246.

[19] Pinto P.C.A.G., SARAiva M.L.M.F.S., Lima J.L.F.C., Sequential injection analysis as a tool for implementation of enzymatic assays in ionic liquids, Talanta, 2008, 77, 479.

[20] Sunitha S., Kanjilal S., Reddy P.S., PRASAD R.B.N., Ionic liquids as a reaction medium for lipase-catalyzed methanolysis of sunflower oil, Biotechnol. Lett., 2007, 29 (12), 1881.

[21] Matzke M., Stolte S., Thiele K., Juffernholz T., Arning J., Ranke J., Welz-Biermann U., JASTORFF B., The influence of anion species on the toxicity of 1-alkyl-3-methylimidazolium ionic liquids observed in an (eco)toxicological test battery, Green Chem., 2007, 9 (11), 1198. 
[22] EN ISO 2871-2. European Standard 2010. Surface active agents. Detergents. Determination of cationic-active matter content. Part 2. Cationic-active matter of low molecular mass (between 200 and 500), Management Centre, Avenue Marnix 17, B-1000 Brussels.

[23] Biczak R., BaŁczewski P., PawŁowska B., Bachowska B., Rychter P., Comparison of phytotoxicity of selected phosphonium ionic liquid, Ecol. Chem. Eng. S, 2014, 21 (2), 281.

[24] MAtzke M., Stolte S., BöSChen A., FILSER J., Mixture effects and predictability of combination effects of imidazolium based ionic liquids as well as imidazolium based ionic liquids and cadmium on terrestrial plants (Triticum aestivum) and limnic green algae (Scenedesmus vacuolatus), Green Chem., 2008, 10, 784.

[25] ZGÓRSKA A., GrabiŃSKA-SOTA E., LisZCZYK G., Evaluation of the influence of ammonium ionic liquid on soil organisms, Przem. Chem., 2010, 89 (7), 55 (in Polish). 